\title{
Patterns and drivers of fish community assembly in a large marine ecosystem
}

\author{
Pécuchet, Lauréne; Törnroos, Anna; Lindegren, Martin
}

Published in:

Marine Ecology - Progress Series

Link to article, DOI:

$10.3354 /$ meps 11613

Publication date:

2016

Document Version

Publisher's PDF, also known as Version of record

Link back to DTU Orbit

Citation $(A P A)$ :

Pécuchet, L., Törnroos, A., \& Lindegren, M. (2016). Patterns and drivers of fish community assembly in a large marine ecosystem. Marine Ecology - Progress Series, 546, 239-248. https://doi.org/10.3354/meps 11613

\section{General rights}

Copyright and moral rights for the publications made accessible in the public portal are retained by the authors and/or other copyright owners and it is a condition of accessing publications that users recognise and abide by the legal requirements associated with these rights.

- Users may download and print one copy of any publication from the public portal for the purpose of private study or research.

- You may not further distribute the material or use it for any profit-making activity or commercial gain

- You may freely distribute the URL identifying the publication in the public portal

If you believe that this document breaches copyright please contact us providing details, and we will remove access to the work immediately and investigate your claim. 


\title{
Patterns and drivers of fish community assembly in a large marine ecosystem
}

\author{
Laurene Pecuchet $^{1, *}$, Anna Törnroos ${ }^{1,2}$, Martin Lindegren ${ }^{1}$ \\ ${ }^{1}$ Centre for Ocean Life, National Institute of Aquatic Resources (DTU-Aqua), Technical University of Denmark, \\ Charlottenlund Castle, 2920 Charlottenlund, Denmark \\ ${ }^{2}$ Åbo Akademi University, Faculty of Science and Engineering, Environmental and Marine Biology, Artillerigatan 6, \\ 20520 Turku, Finland
}

\begin{abstract}
The presence and survival of the species in a community depend on their abilities to maximize fitness in a given environment. The study of the processes that control survival and co-existence, termed 'assembly rules', follows various mechanisms, primarily related to biotic or abiotic factors. To determine assembly rules, ecological similarities of co-occurring species are often investigated. This can be evaluated using trait-based indices summarizing the species' niches in a given community. In order to investigate the underlying processes shaping community assembly in marine ecosystems, we investigated the patterns and drivers of fish community composition in the Baltic Sea, a semi-enclosed sea characterized by a pronounced environmental gradient. Our results showed a marked decline in species- and functional richness, largely explained by decreasing salinities. In addition, habitat complexity and oxygen were found to be significant drivers. Furthermore, we showed that the trait composition of the fish community in the western Baltic Sea is more similar than expected by random chance alone. This implies that environmental filtering, acting along the salinity gradient, is the dominant factor shaping community composition. However, community composition in the eastern part, an area beyond the steep decline in salinity, was characterized by fewer species with largely different trait characteristics, indicating that community assembly is also affected by biotic interactions. Our results add to the knowledge base of key abiotic drivers impacting marine fish communities and their vulnerability to environmental changes, a key concern for fisheries and marine ecosystem management.
\end{abstract}

KEY WORDS: Traits · Demersal fish · Baltic Sea · Assembly rule · Community · Abiotic Competition $\cdot$ Functional richness $\cdot$ Biodiversity

\section{INTRODUCTION}

The presence and survival of the species in a community depend on their capacities to maximize their fitness in a given environment (Drake 1990). Studying the processes that control the survival and coexistence of species within a community, termed 'assembly rules', is a focal point of community ecology (Weiher \& Keddy 1995, Pavoine \& Bonsall 2011). The assembly rules follow various mechanisms and processes primarily related to biotic or abiotic processes (McGill et al. 2006). Biotic control, also known as 'limiting similarity', refers to interspecific competition, which prevents species with similar ecological niches from co-occurring (MacArthur \& Levins 1967). Under strong biotic control, the resulting trait diversity of the community will be high, with the most abundant and co-occurring species having different traits (Mouillot et al. 2007a). In the case of strong abiotic control, known as 'environmental filtering', species that co-exist in the community are likely to share similar ecological traits that enable them to survive in the local environment (Keddy 1992, Violle et al. 2007). Thus, the resulting trait diversity of the 
community will be low (Mouillot et al. 2007a). Unlike these deterministic processes, 'neutral assembly' occurs when community composition follows a stochastic process or when limiting similarity and niche filtering processes act in synergy and cannot be distinguished from each other (Hubbell 2001).

To determine the assembly rules acting on community composition, ecological similarities of co-occurring species are often investigated (Pavoine et al. 2004, Mason et al. 2013). The ecological similarity between species can be evaluated from a number of traits, which refers to any measurable morphological, physiological or phenological feature that affects individual performance, e.g. growth, reproduction and survival (Violle et al. 2007, Mouchet et al. 2013, Mouillot et al. 2013). Therefore, each species can be described by a set of traits that determine its ecological niche. Trait-based indices summarize the trait ranges and values of all the species present in a community and therefore take into account the ecological niches of the species (Petchey \& Gaston 2002, 2006). Trait values are likely to change in relation to environmental gradients or disturbance (McGill et al. 2006, Violle et al. 2012, Mouillot et al. 2013). Studies on assembly rules and trait diversity in the marine environment have primarily been conducted in estuaries (Mouillot et al. 2007a, Mouchet et al. 2013). Under such strong environmental gradients, abiotic control is the dominant process shaping community composition (Laughlin et al. 2011, Venn et al. 2011, Mason et al. 2013). Furthermore, environmental filtering is the most important driver of community composition at large spatial scales (Mouchet et al. 2013). However, biotic control on local community composition, through intraspecific competition, can become preponderant at smaller spatial scales (Jackson \& Harvey 1989).

The Baltic Sea is a large, semi-enclosed sea that receives only limited input of saline and oxygen rich bottom water from the neighbouring North Sea (see Fig. 1). Consequently, the Baltic Sea is characterized by a pronounced environmental gradient illustrated by marked changes in temperature, salinity and oxygen conditions from the Kattegat to the northern Baltic proper (Leppäranta \& Myrberg 2009). This environmental gradient is known to influence species distribution, as only a few marine species are able to reproduce and survive in the cold brackish conditions (Nissling 2002, Ojaveer et al. 2010). Hence, the Baltic Sea is a species-poor ecosystem (Bonsdorff 2006) with a pronounced decrease in richness along the environmental gradient, as shown for benthic macrofauna (Törnroos et al. 2015). Because of this pronounced environmental gradient, the Baltic Sea serves as an ideal marine case study to investigate the underlying processes shaping community assembly and patterns of species richness and trait diversity. In this study, we investigated the trait composition of demersal (bottom-living) fish communities along the Baltic Sea gradient using quantitative scientific trawl survey data and an extensive fish trait database. By comparing spatial patterns of species richness, functional richness and ecological similarity we shed light on the underlying drivers and mechanisms shaping community assembly in one of the large marine ecosystems of the world (Sherman \& Hempel 2008).

\section{MATERIALS AND METHODS}

\section{The Baltic International Trawl Survey (BITS)}

The demersal fish dataset used in this study was extracted from the Baltic International Trawl Survey Database (DATRAS: www.datras.ices.dk). This trawl survey data covers an area from the Kattegat to the northern Baltic proper (Fig. 1). In this area, standard-

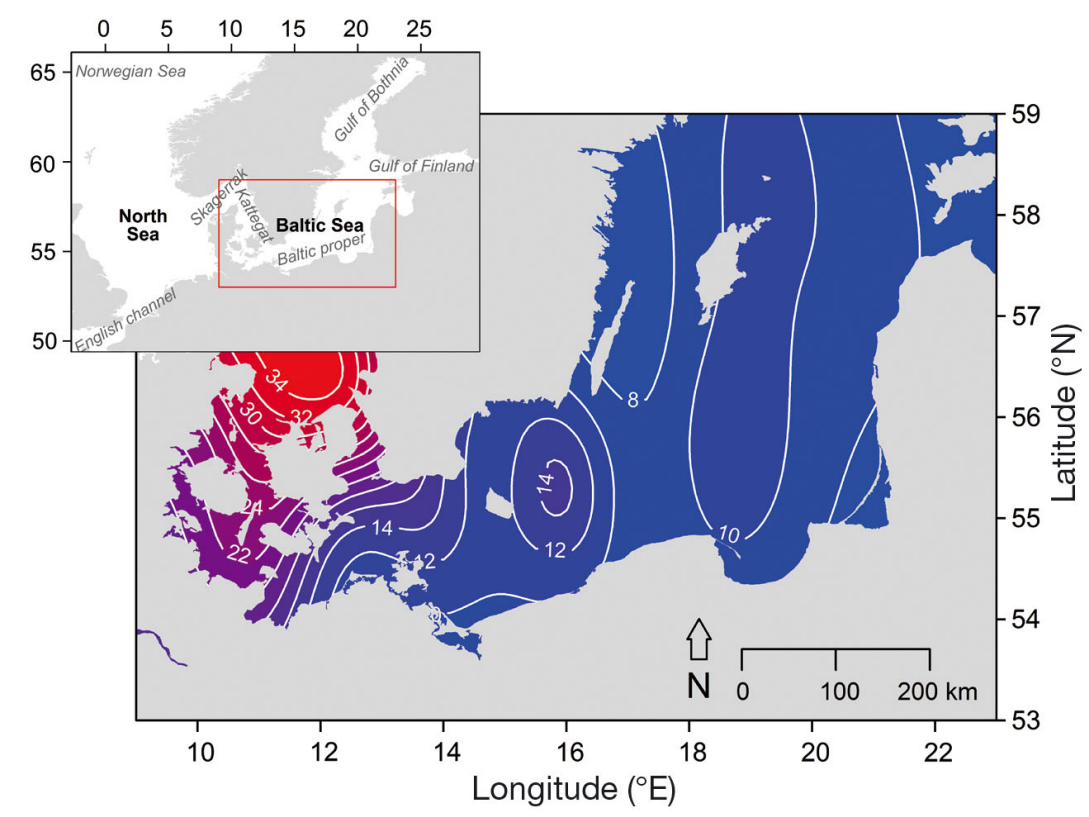

Fig. 1. Baltic Sea and its position relative to northern Europe. Colours and contour lines: pronounced bottom salinity gradient from the Kattegat to the northern Baltic proper 
Table 1. Traits used to define the ecological niche of the species

\begin{tabular}{|c|c|c|c|c|}
\hline Trait & Categories & Description & Relevance & Sources \\
\hline Diet & $\begin{array}{l}\text { Piscivorous } \\
\text { Benthivorous } \\
\text { Planktivorous } \\
\text { Generalist }\end{array}$ & $\begin{array}{l}\text { Main taxonomic group } \\
\text { eaten by the species }\end{array}$ & $\begin{array}{l}\text { Information on food } \\
\text { web structure and } \\
\text { ecological niche } \\
\text { occupation }\end{array}$ & FishBase and literature \\
\hline $\begin{array}{l}\text { Age } \\
\text { at maturity }\end{array}$ & Continuous & $\begin{array}{l}\text { Age at which } 50 \% \\
\text { of the population is } \\
\text { mature }\end{array}$ & $\begin{array}{l}\text { Relates to lifespan } \\
\text { and generation time }\end{array}$ & Literature \\
\hline $\begin{array}{l}\text { Mean } \\
\text { fecundity }\end{array}$ & Continuous & $\begin{array}{l}\text { Average number } \\
\text { of eggs per adult female } \\
\text { during } 1 \text { spawning season }\end{array}$ & $\begin{array}{l}\text { Relates to productivity } \\
\text { of the species }\end{array}$ & FishBase and literature \\
\hline Mean length & Continuous & $\begin{array}{l}\text { Mean total length of } \\
\text { the species in the Baltic Sea } \\
\text { demersal survey }\end{array}$ & $\begin{array}{l}\text { A proxy for many key } \\
\text { traits, often considered } \\
\text { most important trait } \\
\text { in the ocean biosphere. } \\
\text { Information on food web } \\
\text { structure }\end{array}$ & $\begin{array}{l}\text { Mean length record } \\
\text { of the species in the BITS } \\
\text { survey }\end{array}$ \\
\hline $\begin{array}{l}\text { Caudal fin } \\
\text { shape }\end{array}$ & $\begin{array}{l}\text { Rounded } \\
\text { Truncated } \\
\text { Emarginated } \\
\text { Forked } \\
\text { Continuous }\end{array}$ & $\begin{array}{l}\text { The shape of the caudal fin, } \\
\text { similar to the caudal } \\
\text { aspect ratio but categorical }\end{array}$ & $\begin{array}{l}\text { Relates to activity and } \\
\text { habitat }\end{array}$ & Pictures \\
\hline Body shape & $\begin{array}{l}\text { Gadoid-like } \\
\text { Flat } \\
\text { Elongated } \\
\text { Eel-like }\end{array}$ & $\begin{array}{l}\text { The shape of the body, } \\
\text { similar to the body depth/ } \\
\text { total length ratio but } \\
\text { categorical }\end{array}$ & $\begin{array}{l}\text { Relates to habitat and } \\
\text { position in the water } \\
\text { column }\end{array}$ & Pictures \\
\hline
\end{tabular}

ized trawl surveys have been conducted annually in February or March since 1991. However, our analyses were restricted to the contemporary period (2003 to 2014) in order to avoid potential biases due to different sampling methods. At each station, all species present were sorted and recorded, and their lengths measured. When taxonomic recording was not systematically specified to species level, genus level was used. As our focus was on offshore fish communities, hauls sampled at depths $<20 \mathrm{~m}$ were excluded from the dataset to avoid inclusion of coastal fish species. This resulted in a large database comprising approximately 3000 hauls across 70 ICES squares $\left(1^{\circ}\right.$ longitude $\times 0.5^{\circ}$ latitude; a standard spatial grid used for fisheries management). We determined the presence, absence and mean catch-perunit-effort (CPUE) of species per haul and per ICES square. In order to avoid bias due to sampling effort, squares with fewer than 10 hauls were excluded from further calculation, which resulted in a total of 55 ICES squares (see Fig. S1 in the Supplement at www.int-res.com/articles/suppl/m546p239_supp.pdf). To avoid biases due to sporadically occurring species, we only included species that were present in at least one-third of all years, and present in at least 10 hauls. Using this selection criterion we retained 52 species, of which 10 were predominately pelagic. Since the catchability and abundance of pelagic species might be underrepresented in the bottom trawl survey, the analyses were conducted on the 42 demersal species only (see Table S1 in the Supplement).

\section{Trait data}

Information on 6 different traits characterizing diet, habitat and reproduction were gathered for all species included in the study. These traits are complementary as they describe different ecological aspects of the species (Table 1). For morphometric traits, pictures of each species were examined and species were assigned to different categories with respect to 'body shape' and 'caudal fin shape'. Information on diet, fecundity and age at maturity were primarily extracted from FishBase (Froese \& Pauly 2012), but also verified with other sources of information (Table S1). The trait 'mean length' was calculated as the mean total length of all the individuals of a species recorded in the survey, averaged over all age classes. For the quantitative traits fecundity and age 
at maturity, values were collected primarily from the Baltic Sea, but when absent, these data were gathered from neighbouring areas. For some species, trait information was not available; in these cases the data were derived from related species (Table S1).

\section{Diversity indices}

Species richness (SR) and functional richness (FRic) indices were calculated and mapped for each ICES square. SR is the number of unique species present, while FRic represents the portion of the trait space occupied by the community, defined as the convex hull volume that contains all traits present in the community (Villéger et al. 2008). FRic is based on presenceabsence data, and was calculated using the FD package in $\mathrm{R}$, allowing for standardization by the range of traits (Laliberté et al. 2014). Two other facets of trait diversity, namely functional evenness and functional divergence (Villéger et al. 2008), were also calculated using the same package (see Fig. S4 in the Supplement).

\section{FRic vs. null model}

Comparing the FRic of the Baltic Sea communities to values obtained from a null model can help disentangle the relative importance of the assembly rules (Mouillot et al. 2007a). The null model was constructed by calculating a mean FRic for each ICES square, obtained from a randomization process whereby species were randomly drawn from the entire species pool. The randomization matrix was obtained by controlling for both row sums (sites; i.e. ICES squares) and column sums (species) using the 'permatswap()' function in the 'vegan' package in R (Oksanen 2010). This operation was iterated 999 times. The observed FRic values were then compared to the null model and its 50 and $95 \%$ distribution. This comparison enabled a visualization of the continuum and the shifting importance of assembly rules ranging from purely environmental filtering to purely limiting similarity. We considered that observed values within the interquartile range correspond to communities where neither of the assembly rules dominated, thus indicating neutral assembly. On the other hand, observed values below or above the 25 - and $75 \%$-quartile, respectively, indicated communities predominately structured through environmental filtering or limiting similarity. Finally, we considered that communities with observed values below or above the $95 \%$ confidence intervals correspond to communities structured purely through environmental filtering or limiting similarity, respectively.

\section{Weighted functional dissimilarity index}

Assembly rules are generally investigated based on presence-absence data alone (Bellwood \& Hughes 2001, Guillemot et al. 2011). However, this approach disregards important information on the relative abundance of the species considered, since species are given equal weights in the FRic calculation (Götzenberger et al. 2012). Furthermore, the limiting similarity and environmental filtering processes can also impact the abundances (May 1975, Mouillot et al. 2007b), since trait similarity may affect the degree of inter-specific competition and lead to generally lower or higher abundances under limiting similarity and environmental filtering, respectively. Therefore, we considered the abundance distribution within each community by taking into account both the relative abundance and the functional dissimilarity between each pair of species. We refer to this index as the weighted functional dissimilarity (wFDiss). To obtain a finer resolution, we calculated this index per haul instead of per ICES square. This index is similar to the Rao Q index (Rao 1982, Fig. S5 in the Supplement), but represents the mean value of the functional dissimilarity between 2 randomly selected species in the community instead of 2 randomly selected individuals. The wFDiss index is defined as:

$$
\mathrm{wFDiss}=\sum_{i \neq j}^{S} \sum_{j \neq i}^{S} d_{i j} p_{i j}
$$

with $\left(\begin{array}{l}S \\ 2\end{array}\right)$ ij unique combinations, $p_{i j}$ is the relative abundance shared by the pair of species $i$ and $j$ compared to the sum of the total community abundance, $d_{i j}$ represents the functional dissimilarity between 2 species ( $i$ and $j$ ) and was assessed using a Gower distance-based analysis on the species $\times$ trait matrix (Podani 1999). The wFDiss index ranges between 0 and 1. Each pair of species can thus be characterized as having similar $\left(d_{i j}<0.5\right)$ or different $\left(d_{i j}>0.5\right)$ trait attributes. This approach is complementary to the FRic index, as it permits us to visualize if the pattern observed using presence only is also reflected when considering species abundances.

\section{Abiotic data}

To determine which environmental variables best explain the observed diversity patterns, bottom salin- 
ity, temperature and oxygen data were collected for all ICES squares studied from CTD data. In addition, habitat type, habitat dominance and mean bottom depth were included as habitat-related explanatory variables and extracted from the HELCOM database (seabed sediment from the BALANCE project at http://maps.helcom.fi). Habitat type was divided into 5 categories (bedrock, hard complex, hard clay, mud and sand) and defined as the category with highest spatial coverage in each ICES square. Habitat dominance was calculated as the standard deviation of the spatial coverage of the categories in each ICES square (i.e. the higher, the less diverse is the habitat).

\section{Statistical modelling}

FRic and SR were modelled using generalized additive models (GAMs), which allow for potential nonlinearities between response and explanatory variables, e.g. in case of an environmental optimum or saturation. The model equation is given by:

$$
F_{i} \sim \alpha+\sum_{i}^{n} s\left(V_{i}\right)+\varepsilon_{i}
$$

where $F$ is the response variable FRic or SR, $\alpha$ is the intercept, $s$ is the smoothing spline function (Wood 2006), $V_{i \rightarrow n}$ are a priori selected environmental explanatory variables and $\varepsilon$ the Gaussian error term. We applied a stepwise backward selection routine based on minimizing the generalized cross validation (GCV) and likelihood ratio tests to select the most parsimonious set of predictors for each model. The $s$ term was constrained to 3 degrees of freedom $(k=$ $3)$, which allowed for second degree relationships, but restricted flexibility during model fitting. The residuals were normally distributed and spatially uncorrelated (Table S3 in the Supplement).
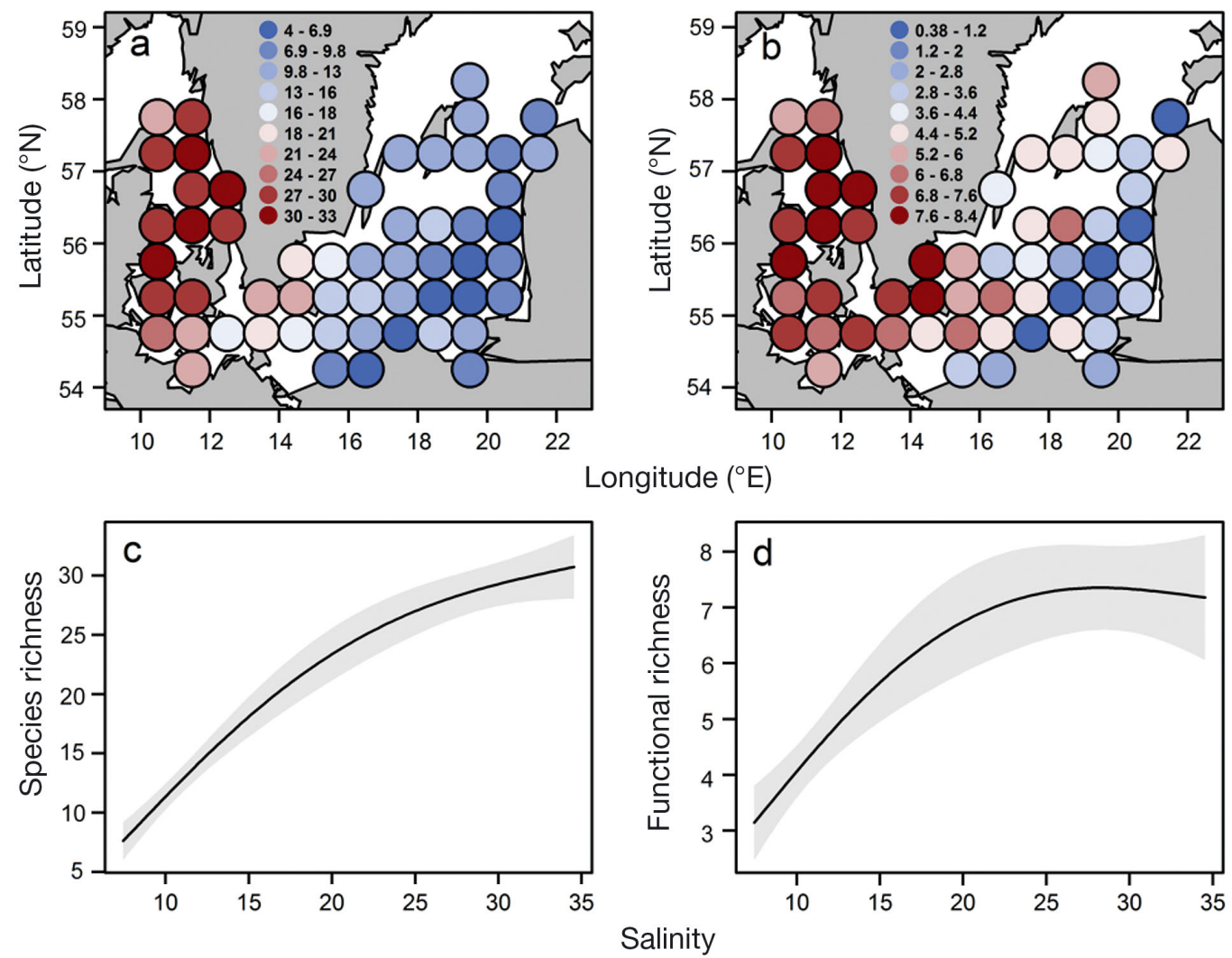

Fig. 2. Spatial patterns of fish (a) species richness and (b) functional richness and (c,d) their corresponding relationships with salinity. In (c,d): Black lines: fitted generalized additive model (GAM); grey shaded areas: SE 
Table 2. Variables and parameters of the final generalized additive models (GAMs). Sign: whether the fitted relationships are predominately positive or negative; edf: estimated degrees of freedom for the model smooth terms (edf $>1$ indicates a nonlinear relationship); DEV: degree of explained variance ${ }^{* * *} \mathrm{p}<0.001$

\begin{tabular}{|c|c|c|c|}
\hline Best models and individual parameters & Sign & edf & $\operatorname{DEV}(\%)$ \\
\hline \multicolumn{4}{|l|}{ Species richness } \\
\hline Best model: salinity + oxygen + habitat & & & 92.5 \\
\hline Salinity $* * *$ & + & 1.91 & \\
\hline Oxygen $^{* * *}$ & + & 0.94 & \\
\hline Habitat ${ }^{* * *}$ & - & 0.94 & \\
\hline Best single variable model: salinity & & & 84.7 \\
\hline Salinity $^{* * *}$ & + & 1.88 & \\
\hline \multicolumn{4}{|l|}{ Functional richness } \\
\hline Best model: salinity + habitat & & & 63.1 \\
\hline Salinity ${ }^{* * *}$ & + & 1.72 & \\
\hline Habitat*** & - & 0.87 & \\
\hline Best single-variable model: salinity & & & 53.8 \\
\hline Salinity ${ }^{* * *}$ & + & 1.81 & \\
\hline
\end{tabular}

ronment, especially by the pronounced salinity gradient which alone explained $84.7 \%$ of the variability (Table 2). SR displayed a positive linear response at low salinity levels until a salinity of approximately 20 ; thereafter the slope decreased but remained positive (Fig. 2c). Habitat dominance and oxygen showed significant negative and positive relationships, respectively, and together with salinity explained $92.5 \%$ of the variability.

FRic followed a similar decreasing pattern as SR, but remained high until 15 to $16^{\circ} \mathrm{E}$ despite a pro- nounced decrease in SR (Fig. 2b). Salinity was the best explanatory variable, explaining $53.8 \%$ of the variability. The relationship between FRic and salinity was characterized by an asymptotic relationship (Fig. 2d). Similar to SR, FRic displayed a positive linear response until a salinity level of 20, but unlike SR it reached an asymptote at salinity levels of 25. FRic had a wider confidence interval, hence a weaker relationship with salinity. Habitat dominance exhibited a significant negative relationship and together with salinity explained $63.1 \%$ of the variability.

\section{FRic vs. null model}

FRic and SR showed a saturating relationship, whereby after a certain level of SR (about 20 species), an increase in SR did not further increase FRic. The observed relationship saturated earlier than the null model and reached a lower asymptote (Fig. 3a). For low SR ( $<15$ species), the observed FRic values were primarily distributed within the interquartile range of the null distribution. However, several communities had observed values in the upper quartile or even above the $97.5^{\text {th }}$ percentile. At higher levels of SR ( $>25$ species), FRic was largely distributed in the lower quartiles or below the $2.5^{\text {th }}$ percentile of the null distribution. The observed communities with high SR but low FRic were primarily found in the western part of the study area (Katte-
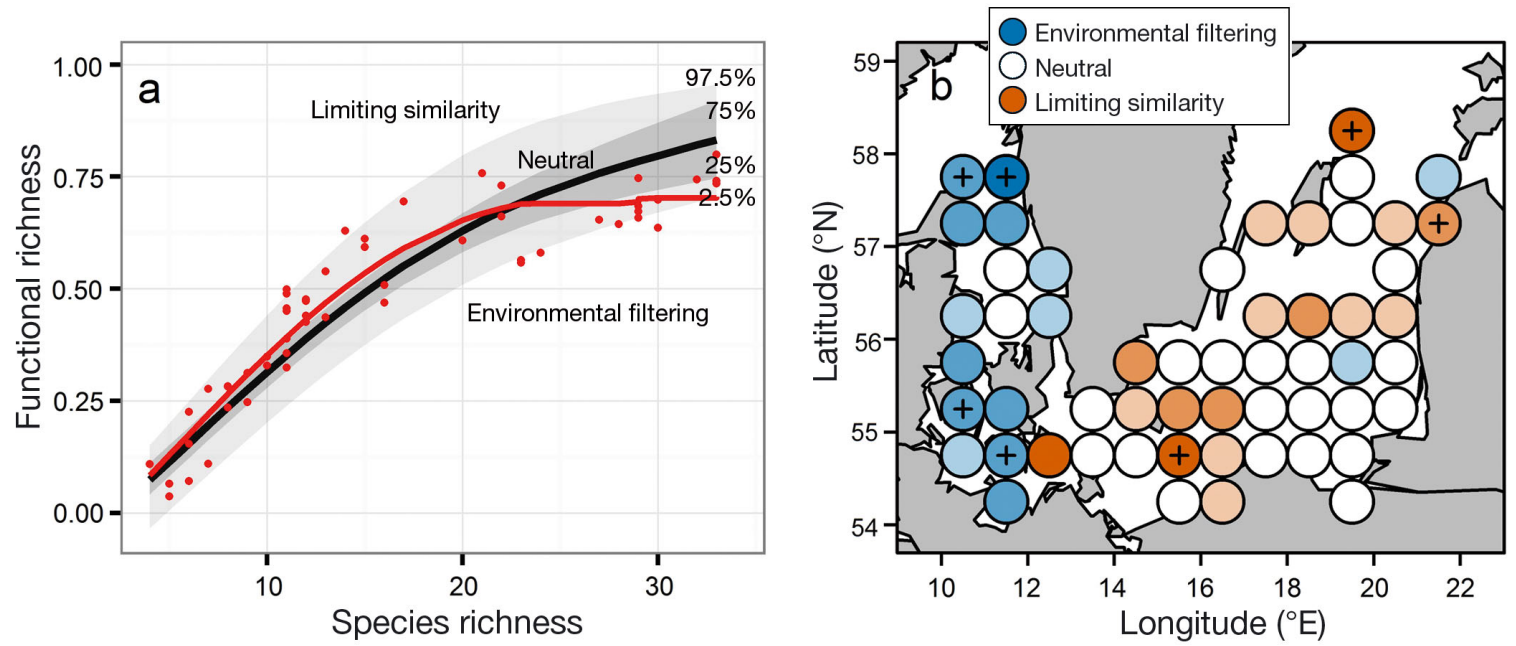

Fig. 3. (a) Observed (red dots) and simulated functional richness (FRic) values based on a null model. Bold black line: mean of 999 random permutations; areas shaded in dark and light grey: $50^{\text {th }}$ and $95^{\text {th }}$ percentiles, respectively, smoothed using a generalized additive model (GAM) function; red line: smooth (GAM) of the observed FRic. (b) Map of the differences (residuals) between observed and simulated FRic, in which values within the interquartile range are represented as 'neutral' assembly rules (white), while values below the $25 \%$ and above the $75 \%$ distribution are represented as 'environmental filtering' (blue) and 'limiting similarity' (orange) assembly rules, respectively. Black crosses: communities significantly different from the null model (outside the $95 \%$ range), where environmental filtering or limiting similarity alone impact community composition 


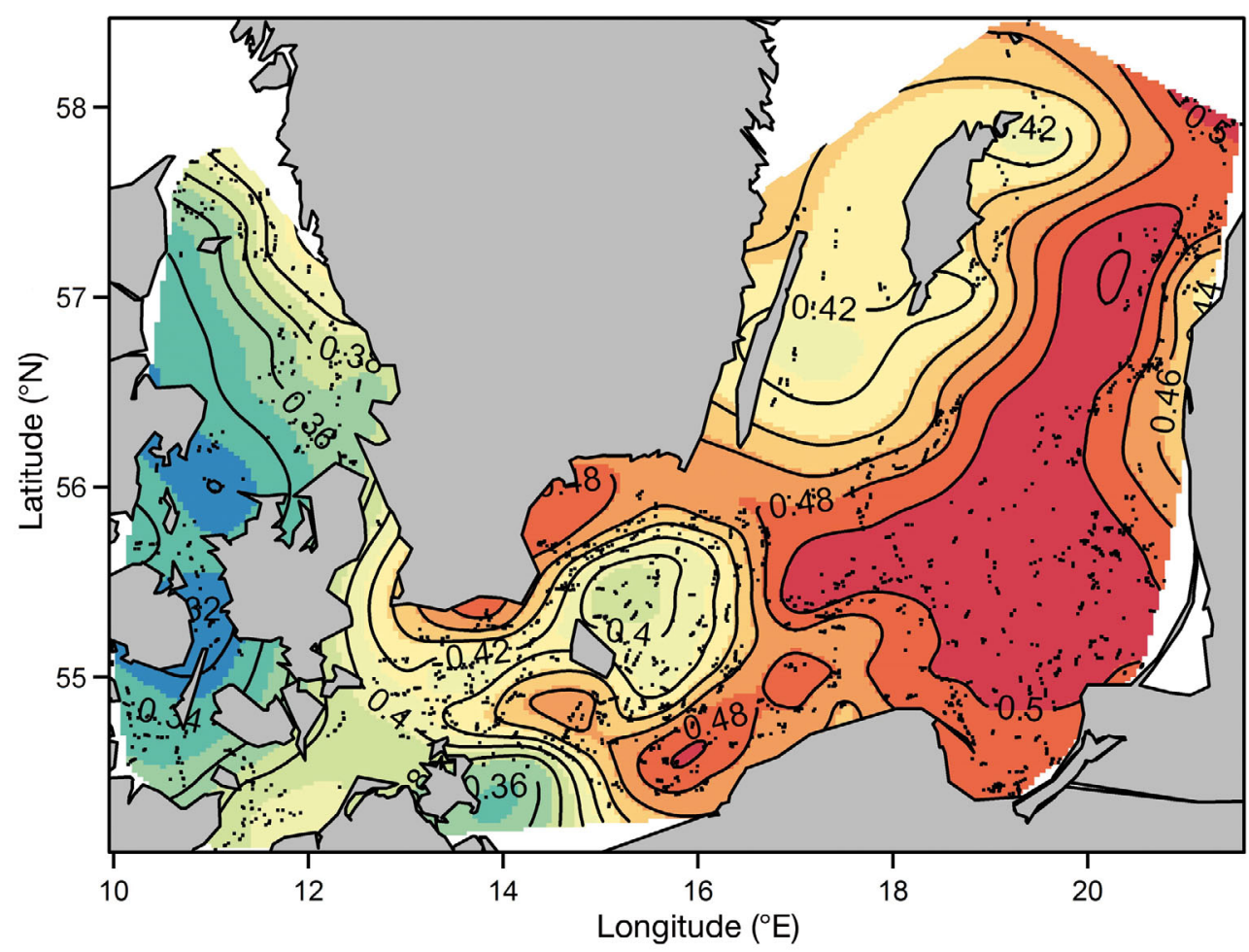

Fig. 4. Spatial patterns of weighted functional dissimilarity (wFDiss) when pairwise species abundances are considered on a per haul basis (black points), smoothed using a thin plate spline regression. Communities with low wFDiss are represented in blue; communities with comparatively higher wFDiss are represented in red. Note that the colour scheme represents only the qualitative distribution of the wFDiss values and does not imply significance gat), while east of $14^{\circ} \mathrm{E}$ (Baltic proper), communities had low SR but comparatively high FRic (Fig. 3b).

\section{Weighted functional dissimilarities of local communities}

The wFDiss index demonstrates a clear spatial structure (Fig. 4). Communities with low wFDiss (i.e. with abundant species sharing similar traits) were primarily present in the western part of the region. Communities with wFDiss close to a neutral value ( 0.45 to 0.55 ) and therefore containing species having neither similar nor dissimilar trait attributes, were mainly located east of $15^{\circ} \mathrm{E}$. Although wFDiss demonstrated a similar west-east pattern, it differed from the spatial patterns of FRic as its values remained low in several areas, even east of $14^{\circ} \mathrm{E}$.

\section{DISCUSSION}

Environmental filtering has been shown to shape community composition along environmental gradients in terrestrial (Diaz et al. 1998, Lebrija-Trejos et al. 2010) and estuarine ecosystems (Mouillot et al. 2007a, Mouchet et al. 2013). Here, we show that environmental filtering is also the primary factor influencing fish community assembly in one of the world's large marine ecosystems, the Baltic Sea. The key underlying driver was a pronounced salinity gradient along which spatial patterns in fish community composition are structured. This is clearly illustrated by a pronounced decline in SR and FRic from maximum values in the Kattegat to minimum values in the eastern Baltic proper. This pattern is in accordance with previous studies on zoobenthos (Bonsdorff 2006, Törnroos et al. 2015) and complies with the so-called Remane's curve, which postulates species richness to be highest at salinities around 35 , decreasing sharply until reaching a minimum at salinities of 6 to 8 , where growth and survival of both freshwater and marine species are compromised (Remane 1934). While the salinity gradient explained most of the spatial patterns, especially in terms of SR, habitat dominance and oxygen accounted for some of the remaining variance. This means that in addition to salinity, a higher degree of bottom complexity and favourable oxygen conditions may allow for higher SR by creating more niches in terms of habitat and benthic food availability (Törnroos et al. 2013). However, a relatively high degree of variance in FRic remained unexplained $(\sim 35 \%)$, suggesting that other environmental variables not included in this study might affect the trait composition of fish communities in the Baltic Sea. Identifying these additional drivers merits further attention. 
The observed relationship between FRic and SR saturated for lower SR levels than the null model. This relationship can be explained by the recurrence of particular species' traits that can be largely attributed to a number of species (e.g. Solea solea, Scophthalmus rhombus, Melanogrammus aeglefinus, Trisopterus minutus) present only in the western species-rich region. These primarily flatfish and gadoid species share similar traits in terms of morphology, fecundity and diet preferences. The high number of functionally similar species may therefore explain why the western communities had lower FRic values than would be expected at random. However, community composition in the eastern part of the area was characterized by a lower number of species with largely different trait characteristics. Hence, FRic values were similar or higher than expected by chance, indicating that biotic interactions may also shape community composition in these areas. Similar spatial patterns in assembly rules were also evident when using the abundance weighted wFDiss index.

The clear distinction between environmental filtering acting in the western Baltic Sea and neutral or limiting similarity acting in the east could potentially be explained by the hydrographic characteristics of the region. The western area is characterized by an unstable environment in which salinity decreases from fully marine to brackish conditions within a very short distance (approximately $400 \mathrm{~km}$ ), whereas in the eastern part, salinity levels are low but comparatively stable, ranging from 14 in the deeper parts to 6 in shallower areas. The steep salinity gradient in the western part of the Baltic may therefore act as a filter, which would allow only species with similar key traits to survive. In the east, species poorly adapted to low salinity levels would be filtered out and the abiotic pressure would be lower, which in turn would give more room for biotic processes to impact community composition. Hence, in this area the community composition mainly follows a neutral or a limiting similarity assembly rule, possibly with both environmental filtering and limiting similarities at work.

In both areas, a few abundant and commercially exploited species (e.g. Gadus morhua, Limanda limanda, Merlangius merlangius, Platichthys flesus and Pleuronectes platessa) constitute most of the demersal fish abundance. Due to the commercial value of the species, fisheries could potentially impact their local abundances, and thus affect the observed patterns in wFDiss. However, fishing likely has little or no impact on the observed patterns of FRic, as the latter is based on presence-absence data only. The close resemblance between spatial patterns of assembly rules derived from both metrics, excluding (FRic) or including (wFDiss) abundances, suggest that the overall patterns are fairly robust to fishing. Nevertheless, systematic differences between the 2 indices, when accounting for the different spatial scales at which they are calculated (i.e. ICES squares vs. per hauls), may shed light on potential fishing effects.

Distinguishing which assembly rule controls community composition can provide knowledge about the biotic or abiotic drivers impacting communities, as well as provide important insight into the vulnerability of the communities to environmental changes (Keddy 1992, Mouillot et al. 2013). Functional trait diversity has a positive impact on the health and functioning of an ecosystem (Diaz \& Cabido 2001, Cadotte et al. 2011, Mora et al. 2011). The study of community composition along the structuring salinity gradient of the Baltic Sea can be used to estimate how functional richness and species richness will adjust due to the predicted changes in abiotic variables under climate change. In the Baltic proper, salinity is projected to decrease by 0.5 to $5 \mathrm{psu}$, depending on the climate model scenario followed (Meier 2006). The consequences of a salinity decrease on fish communities can hence be visualized as a shift in the observed pattern with fewer marine species entering the Baltic proper. Salinity changes will likely have different impacts on SR and FRic. Due to an almost linear relationship with salinity, SR can be forecasted to change proportionally to the salinity decrease, while FRic might show only a minor decrease due to its asymptotic relationship. Nonetheless, we have shown that functional richness is already lower than expected from a null model, hence only a slight decrease could have severe consequences for the functioning and health of the ecosystem. The Baltic Sea is a complex socio-ecological system. Being bordered by 9 countries, it is subject to high anthropogenic pressures. Therefore, in an already highly impacted ecosystem, understanding the processes that structure community composition and the main abiotic drivers is of key concern for ecosystem management efforts striving to maintain a healthy and productive system, now and in the future.

Acknowledgements. The study was conducted within the Centre for Ocean Life, a VKR center of excellence supported by the Villum foundation. A.T. was funded through the BONUS BIO-C3 project, and thus this work resulted from the BONUS BIO-C 3 project and was supported by BONUS (Art 185), funded jointly by the EU. We are also grateful to all the scientific and crew members engaged in the Baltic International Trawl Survey, as well as 2 reviewers for their valuable comments. 


\section{LITERATURE CITED}

Bellwood DR, Hughes TP (2001) Regional-scale assembly rules and biodiversity of coral reefs. Science 292: 1532-1535

Bonsdorff E (2006) Zoobenthic diversity-gradients in the Baltic Sea: continuous post-glacial succession in a stressed ecosystem. J Exp Mar Biol Ecol 330:383-391

Cadotte MW, Carscadden K, Mirotchnick N (2011) Beyond species: functional diversity and the maintenance of ecological processes and services. J Appl Ecol 48: 1079-1087

$>$ Diaz S, Cabido M (2001) Vive la différence: plant functional diversity matters to ecosystem processes. Trends Ecol Evol 16:646-655

Diaz S, Cabido M, Casanoves F (1998) Plant functional traits and environmental filters at a regional scale. J Veg Sci 9: 113-122

Drake JA (1990) The mechanics of community assembly and succession. J Theor Biol 147:213-233

Froese R, Pauly D (eds) (2012) FishBase. www.fishbase.ca

> Götzenberger L, de Bello F, Bråthen KA, Davison J and others (2012) Ecological assembly rules in plant communities-approaches, patterns and prospects. Biol Rev Camb Philos Soc 87:111-127

Guillemot N, Kulbicki M, Chabanet P, Vigliola L (2011) Functional redundancy patterns reveal non-random assembly rules in a species-rich marine assemblage. PLoS ONE 6:e26735

Hubbell SP (2001) The unified neutral theory of biodiversity and biogeography. Princeton University Press, Princeton, NJ

Jackson DA, Harvey HH (1989) Biogeographic associations in fish assemblages: local vs. regional processes. Ecology 70:1472-1484

Keddy PA (1992) Assembly and response rules: two goals for predictive community ecology. J Veg Sci 3:157-164

Laliberté E, Legendre P, Shipley B (2014) FD: measuring functional diversity from multiple traits, and other tools for functional ecology. R package version 10-12, https: //cran.r-project.org/web/packages/FD/index.html

Laughlin DC, Fulé PZ, Huffman DW, Crouse J, Laliberté E (2011) Climatic constraints on trait-based forest assembly. J Ecol 99:1489-1499

Lebrija-Trejos E, Perez-Garcia E, Meave JA, Bongers F, Poorter L (2010) Functional traits and environmental filtering drive community assembly in a species-rich tropical system. Ecology 91:386-398

Leppäranta M, Myrberg K (2009) Physical oceanography of the Baltic Sea. Springer, Berlin

> MacArthur R, Levins R (1967) The limiting similarity, convergence, and divergence of coexisting species. Am Nat 101:377-385

Mason NWH, de Bello F, Mouillot D, Pavoine S, Dray S (2013) A guide for using functional diversity indices to reveal changes in assembly processes along ecological gradients. J Veg Sci 24:794-806

May R (1975) Patterns of species abundance and diversity. In: Cody ML, Diamond JM (eds) Ecology and evolution of communities. Harvard University Press, Cambridge, MA

McGill BJ, Enquist BJ, Weiher E, Westoby M (2006) Rebuilding community ecology from functional traits. Trends Ecol Evol 21:178-185

Meier HEM (2006) Baltic Sea climate in the late twenty-first century: a dynamical downscaling approach using two global models and two emission scenarios. Clim Dyn 27: $39-68$

Mora C, Aburto-Oropeza O, Ayala Bocos A, Ayotte PM and others (2011) Global human footprint on the linkage between biodiversity and ecosystem functioning in reef fishes. PLoS Biol 9:e1000606

> Mouchet MA, Burns MDM, Garcia AM, Vieira JP, Mouillot D (2013) Invariant scaling relationship between functional dissimilarity and co-occurrence in fish assemblages of the Patos Lagoon estuary (Brazil): environmental filtering consistently overshadows competitive exclusion. Oikos 122:247-257

Mouillot D, Dumay O, Tomasini JA (2007a) Limiting similarity, niche filtering and functional diversity in coastal lagoon fish communities. Estuar Coast Shelf Sci 71: 443-456

> Mouillot D, Mason NWH, Wilson JB (2007b) Is the abundance of species determined by their functional traits? A new method with a test using plant communities. Oecologia 152:729-737

Mouillot D, Graham NAJ, Villéger S, Mason NWH, Bellwood DR (2013) A functional approach reveals community responses to disturbances. Trends Ecol Evol 28: 167-177

Nissling A (2002) Reproductive success in relation to salinity for three flatfish species, dab (Limanda limanda), plaice (Pleuronectes platessa), and flounder (Pleuronectes flesus), in the brackish water Baltic Sea. ICES J Mar Sci 59: 93-108

Ojaveer H, Jaanus A, Mackenzie BR, Martin G and others (2010) Status of biodiversity in the Baltic Sea. PLoS ONE 5:e12467

Oksanen J (2010) Vegan: ecological diversity. R package version 2.3, https://cran.r-project.org/web/packages/ vegan/index.html

> Pavoine S, Bonsall MB (2011) Measuring biodiversity to explain community assembly: a unified approach. Biol Rev Camb Philos Soc 86:792-812

> Pavoine S, Dufour AB, Chessel D (2004) From dissimilarities among species to dissimilarities among communities: a double principal coordinate analysis. J Theor Biol 228: 523-537

Petchey OL, Gaston KJ (2002) Functional diversity (FD), species richness and community composition. Ecol Lett 5: 402-411

Petchey OL, Gaston KJ (2006) Functional diversity: back to basics and looking forward. Ecol Lett 9:741-758

Podani J (1999) Extending Gower's general coefficient of similarity to ordinal characters. Taxon 48:331-340

Rao CR (1982) Diversity and dissimilarity coefficients: a unified approach. Theor Popul Biol 21:24-43

Remane A (1934) Die Brackwasserfauna. Verh Dtsch Zool Ges 36:34-74

Sherman K, Hempel G (2008) The UNEP large marine ecosystem report: a perspective on changing conditions in LMEs of the world's regional seas. UNEP Regional Seas Report and Studies No. 182. United Nations Environment Programme, Nairobi

- Törnroos A, Nordström MC, Bonsdorff E (2013) Coastal habitats as surrogates for taxonomic, functional and trophic structures of benthic faunal communities. PLoS ONE 8:e78910

Törnroos A, Bonsdorff E, Bremner J, Blomqvist M, Josefson AB, Garcia C, Warzocha J (2015) Marine benthic eco- 
logical functioning over decreasing taxonomic richness. J Sea Res 98:49-56

Venn SE, Green K, Pickering CM, Morgan JW (2011) Using plant functional traits to explain community composition across a strong environmental filter in Australian alpine snowpatches. Plant Ecol 212: 1491-1499

Villéger S, Mason NWH, Mouillot D (2008) New multidimensional functional diversity indices for a multifaceted framework in functional ecology. Ecology 89: 2290-2301

Editorial responsibility: Kenneth Sherman, Narragansett, Rhode Island, USA
Violle C, Navas ML, Vile D, Kazakou E, Fortunel C, Hummel I, Garnier E (2007) Let the concept of trait be functional! Oikos 116:882-892

Violle C, Enquist BJ, McGill BJ, Jiang L and others (2012) The return of the variance: intraspecific variability in community ecology. Trends Ecol Evol 27:244-252

Weiher E, Keddy PA (1995) Assembly rules, null models, and trait dispersion: new questions from old patterns. Oikos 74:159-164

Wood SN (2006) Generalized additive models: an introduction with R. CRC Press, Boca Raton, FL

Submitted: September 3, 2015; Accepted: January 13, 2016 Proofs received from author(s): March 8, 2016 